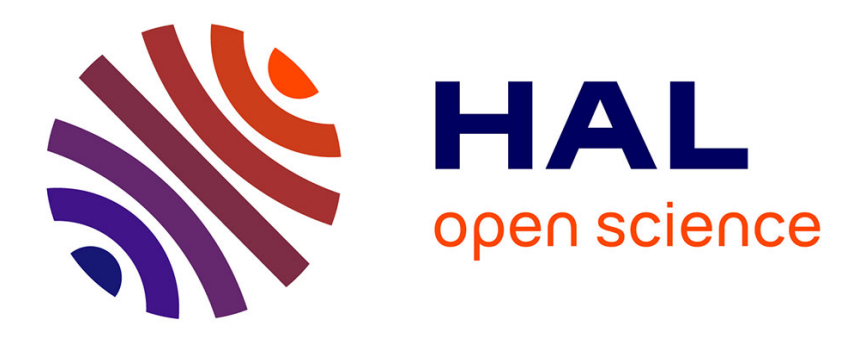

\title{
The acquisition of pronominal case-marking by Japanese learners of English
}

Koji Suda, Shigenori Wakabayashi

\section{To cite this version:}

Koji Suda, Shigenori Wakabayashi. The acquisition of pronominal case-marking by Japanese learners of English. Second Language Research, 2007, 23 (2), pp.179-214. 10.1177/0267658307076545 . hal00570726

\section{HAL Id: hal-00570726 \\ https://hal.science/hal-00570726}

Submitted on 1 Mar 2011

HAL is a multi-disciplinary open access archive for the deposit and dissemination of scientific research documents, whether they are published or not. The documents may come from teaching and research institutions in France or abroad, or from public or private research centers.
L'archive ouverte pluridisciplinaire HAL, est destinée au dépôt et à la diffusion de documents scientifiques de niveau recherche, publiés ou non, émanant des établissements d'enseignement et de recherche français ou étrangers, des laboratoires publics ou privés. 


\title{
The acquisition of pronominal case-marking by Japanese learners of English
}

\section{Koji Suda Sendai National College of Technology and Shigenori Wakabayashi Chuo University}

Received June 2003; revised October 2005; accepted November 2005

\begin{abstract}
Eighty-one seventh- and eighth-grade students (age 12-14) learning English in Japanese classrooms were tested on their knowledge of English case-marked pronouns in sentences like He likes her, *He likes she and *Him likes her. The aim of the study was to evaluate the predictions of three theories of second language (L2) development against the results obtained. Given the case-marking properties of Japanese, the Full Transfer/Full Access model of Schwartz (1998) and Schwartz and Sprouse (1994; 1996; 2000), the Minimal Trees model of Vainikka and Young-Scholten (1994; 1996a; 1996b; 1998) and the Lexical Learning/Lexical Transfer model of Wakabayashi $(1997$; 2002) make different predictions about the kinds of patterns of case-marked pronouns that will be found in the second language English of early learners with Japanese first language (L1). It is argued that the results are consistent with the predictions of the Lexical Learning/Lexical Transfer model, but with neither Full Transfer/Full Access nor Minimal Trees.
\end{abstract}

\section{Introduction}

This study examines the acquisition of pronominal case-marking by Japanese learners of English (JLEs). Data were collected from seventhand eighth-grade students (age 12-14) in Japan. We analyse data from individual participants and examine to what extent JLEs acquire lexical items in English, and to what extent they transfer properties from 
Japanese. Moreover, we discuss the plausibility of three second language acquisition (SLA) models, namely the Full Transfer/Full Access (FT/FA) model of Schwartz (1998) and Schwartz and Sprouse (1994; 1996; 2000), the Minimal Trees (MT) model of Vainikka and YoungScholten (1994; 1996a; 1996b; 1998) and the Lexical Learning/Lexical Transfer (LL/LT) model of Wakabayashi (1997; 2002).

The article is organized as follows. In Section II, differences between the English and Japanese case systems are described, and an overview of Case checking as defined within the Minimalist Program of Chomsky (1995) is given. In addition, since word order is closely related to Case checking, differences between English and Japanese with respect to word order are discussed. In Section III, the predictions for the acquisition of overt case-marking in English by Japanese speakers are outlined. In Section V, results of an experiment testing these predictions will be presented. In Section VI, examining data from individual participants, we argue for developmental sequences in JLEs' interlanguage grammars. Furthermore, based on this argument, the plausibility of the three SLA models is discussed. Section VII concludes the article.

\section{Linguistic background}

\section{Differences between the case systems}

There are two differences between the English and Japanese case systems. One is how abstract Case is marked in general and the other involves object case-marking specifically. We will now look more closely at those differences.

a Case-marking: In English, only pronouns are morphologically marked for Case (1a), whereas noun phrases are not morphologically marked (1b).

1) a. She hits him.

b. Mary hits John.

The sentence (1a) has two pronouns, where the subject She has nominative Case and the object him has accusative Case, and their Cases are thus overtly marked. On the other hand, in (1b), neither the subject Mary nor the object John exhibits Case. By contrast, every noun phrase 
in Japanese is morphologically marked as to its Case by a post-positional case-marker, although it can be dropped in some cases (Kuno, 1973; Saito, 1985; Suzuki, 1999). For instance, in (2a) and (2b), the Case-marker $g a$ indicates the nominative Case of both the pronoun kanozyo (third person singular female pronoun) and the noun phrase Mary, while the Case-marker $o$ shows the accusative Case of both the pronoun kare (third person singular male pronoun) and the noun phrase John.

2) a. kanozyo-ga kare-o tataku

kshe-Nom he-Acc hit

'She hits him.'

b. Mary-ga John-o tataku

Mary-Nom John-Acc hit

'Mary hits John.'

$b$ Object case-marking: There are two types of verbs with different case-marking properties in Japanese. One type typically represents actions, and the other states. For instance, yоти 'read' and tataku 'hit' stand for actions, while wakaru 'understand' and suki 'like' correspond to states. ${ }^{1}$ We call the former type of verbs non-stative verbs and the latter type stative verbs (e.g. Kuno, 1973; Saito, 1982; Shibatani, 1990; Tateishi, 1991; Mihara, 1994; Koizumi, 1995; Ura, 1996; Takezawa and Whitman, 1998). ${ }^{2}$ Note that this division is a syntactic one so that it can play an important role with respect to object case-marking in Japanese.

When a non-stative verb is used, the object noun phrase is only marked with the accusative case-marker $o$, but not by the nominative Case-marker ga. In (3), a non-stative verb tataku 'hit' is used. Therefore, the object John is marked with the accusative Case-marker $o$ in (3a), and this sentence is grammatical. However, in (3b), the object

${ }^{1}$ Traditionally, stative verbs include adjective-verbs (na-adjectives) and adjectives (i-adjectives) in Japanese. The $n a$-adjectives, $i$-adjectives and verbs are all inflected for tense, and most generative linguists (e.g. Mihara, 1994; Takezawa and Whitman, 1998) assume that their categorial features are $\mathrm{V}$ when they are the head of a predicate. We follow this line of analysis and treat them as V.

${ }^{2}$ There are true stative verbs such as wakaru 'understand', mieru 'be able to see' and dekiru 'be able to do', which resist the ga/o alternation for object case-marking. When a true stative verb is used, the object is marked with the nominative case-marker $g a$, and the use of the accusative case-marker $o$ is not allowed as in (i):

i) Ken-wa furansugo-ga/*-o wakaru

Ken-Top French-Nom/*-Acc understand

'Ken understands French'

We do not deal with such true stative verbs in this article since it is difficult to use personal pronouns as objects when they are used. 
is marked with the nominative case-marker $g a$, and this sentence becomes ungrammatical.

3) a. Mary-ga John-o tataku

Mary-Nom John-Acc hit

'Mary hits John'

b. * Mary-ga John-ga tataku

Mary-Nom John-Nom hit

On the other hand, when a stative verb is used, the object noun phrase can be marked with either the accusative case-marker $o$ or the nominative case-marker $g a$. For instance, in (4), a stative verb sukida 'like' is used. Therefore, the object John is marked with the accusative casemarker $o$ in (4a), while the object John is marked with the nominative case-marker $g a$ in (4b), and both sentences are grammatical.

4) a. Mary-ga John-o sukida

Mary-Nom John-Acc like

'Mary likes John.'

b. Mary-ga John-ga sukida

Mary-Nom John -Nom like

'Mary likes John.'

In short, the object can be marked with the nominative case-marker $g a$ when stative verbs are used, but not when non-stative verbs are used.

On the other hand, there is no such case-marking variation in English. Object pronouns must appear in their accusative forms regardless of the type of verbs as in (5).

5) a. She hits/likes him.

b. * She hits/likes he.

In (5a), the object pronoun takes the accusative form him, and the use of the nominative form he is not allowed.

\section{Case checking}

The computational system of the Minimalist Program (Chomsky, 1995) is assumed here. In that system, sentences are derived in the manner shown in Figure 1. Before the derivation starts, lexical items are taken into the numeration in the Lexicon. In the derivation, they are put together to make larger constituents through the operation 'Merge'. In Chomsky's 1995 model, some features of lexical items need to be 


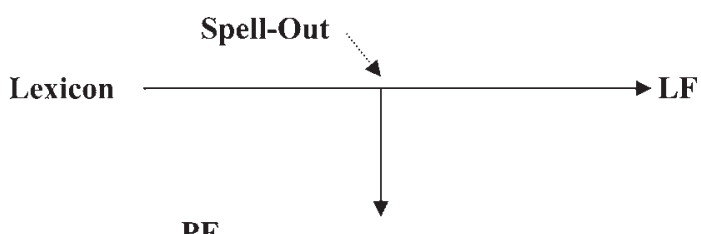

PF

Figure 1 Derivation in the Minimalist Program

licensed by other features. Without such licensing, the derivation would 'crash' (not produce a grammatical outcome). This is known as 'feature checking'. Feature checking is not accomplished by 'Merge' but by the operation 'Attract/Move'. When all operations that affect the pronunciation of the structure are finished, the syntactic object is spelled out (Spell-Out in Figure 1) and presented to the level of Phonetic Form $(\mathrm{PF})$. If further operations are needed for the syntactic object to be interpreted, the relevant operations take place at Logical Form (LF), where the syntactic object is interpreted.

The operation relevant to this study is Case checking. Chomsky (1995: 178-79) assumes that Case checking always takes place within the domain of functional heads under the specifier-head (Spec-head) relation. Moreover, Chomsky (1995: 351-52) proposes that a functional category $\mathrm{T}$ provides the domain for nominative Case checking and a light verb $v$ does so for accusative Case checking in a simple transitive sentence.

Based on these minimalist assumptions, Case checking in English and Japanese is now described.

a Case checking in English: In English, a subject in finite clauses always has nominative Case [Nom] and an object always has accusative Case [Acc] regardless of the type of verbs. It is assumed that the nominative Case of a subject is checked against that of $\mathrm{T}$ in Tense Phrase (TP) and the accusative Case of an object is checked against that of $\mathrm{V}$ in verb Phrase ( $v \mathrm{P})$ (Chomsky, 1995; Culicover, 1997; Radford, 1997). The nominative Case of $\mathrm{T}$ is strong since there is subject-verb agreement in English (see Chomsky, 1995: 360-61). ${ }^{3}$ Since strong Case requires overt raising, the nominative Case with She overtly moves to the

${ }^{3}$ Chomsky (2000) introduces a new operation 'Agree', and feature strength is no longer used as an explanation of movement. However, we follow Chomsky (1995) and do not deal with these more recent changes to the model here. 


\section{The acquisition of pronominal case-marking}

specifier position of $\mathrm{T}$ from that of $\mathrm{VP}$ through $v \mathrm{P}$, and the Case is checked off against that of $T$ by the Spec-head relation in TP. In contrast, the accusative Case of V is weak because there is no verb-object agreement in English (see Chomsky, 1995: 360-61), and it requires covert raising of the accusative Case. Consequently, only the accusative Case of him covertly moves to the specifier position in $v \mathrm{P}$ after $\mathrm{V}$ with the accusative Case (hits/likes [Acc]) moves and adjoins to $v$. Then, both Cases are eliminated by the Spec-head relation in $v \mathrm{P}$. When $\mathrm{T}, v$ and $\mathrm{V}$ are included in the numeration, the syntactic structure, as in (6), is spelled out. ${ }^{4}$

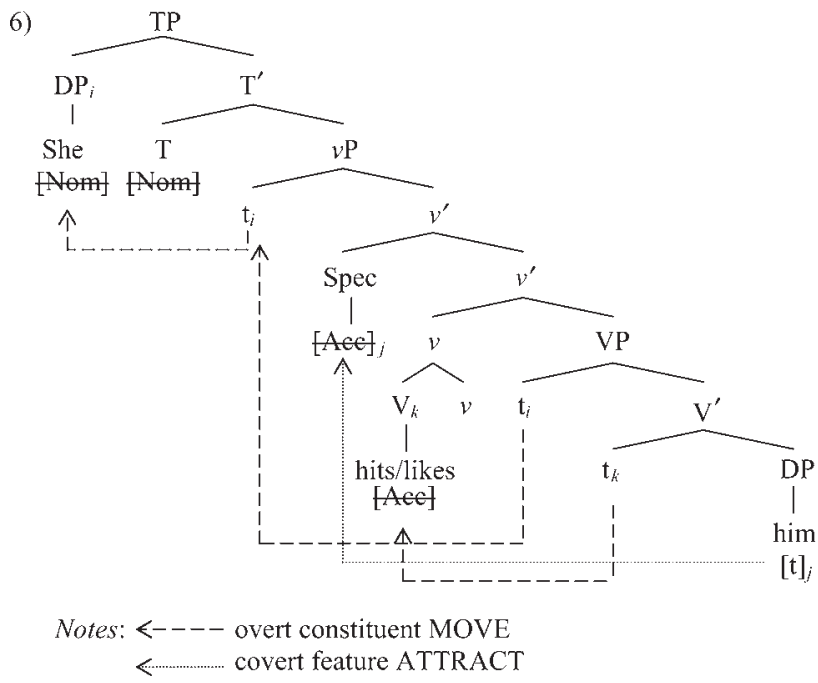

In short, the nominative Case of a subject is checked off by that of $\mathrm{T}$ after She with [Nom] overtly moves to the specifier position of $\mathrm{T}$, while the accusative Case of an object is checked off by that of V only after the Case covertly raises to the specifier position of $v$. By these operations, those Cases are uniformly eliminated within the Spec-head relation in TP and $\nu \mathrm{P}$.

$b$ Case checking in Japanese: As we have seen, post-positional casemarkers overtly mark Cases in Japanese. When a noun phrase is marked with the nominative case-marker $g a$, we assume that it has nominative

${ }^{4}$ Chomsky (1995) assumes that the subject is base-generated in the specifier position of $v P$. However, we follow the VP-internal subject hypothesis (Kitagawa, 1986; Kuroda, 1988), and tree diagrams are different from those in Chomsky (1995). 
case. On the other hand, when a noun phrase is marked with the accusative case-marker $o$, it has accusative Case. When the subject kanozyo in (7) is marked with the nominative case-marker $g a$ and the object kare bears the accusative case-marker $o$, we assume that $\mathrm{T}, v$ and $\mathrm{V}$ are included in the numeration and the syntactic structure spelled out is projected as in (7). Japanese is a head-final language in contrast to English. However, as in English, TP directly dominates $v \mathrm{P}$, and $v \mathrm{P}$ directly dominates VP.

7) $\mathrm{TP}$

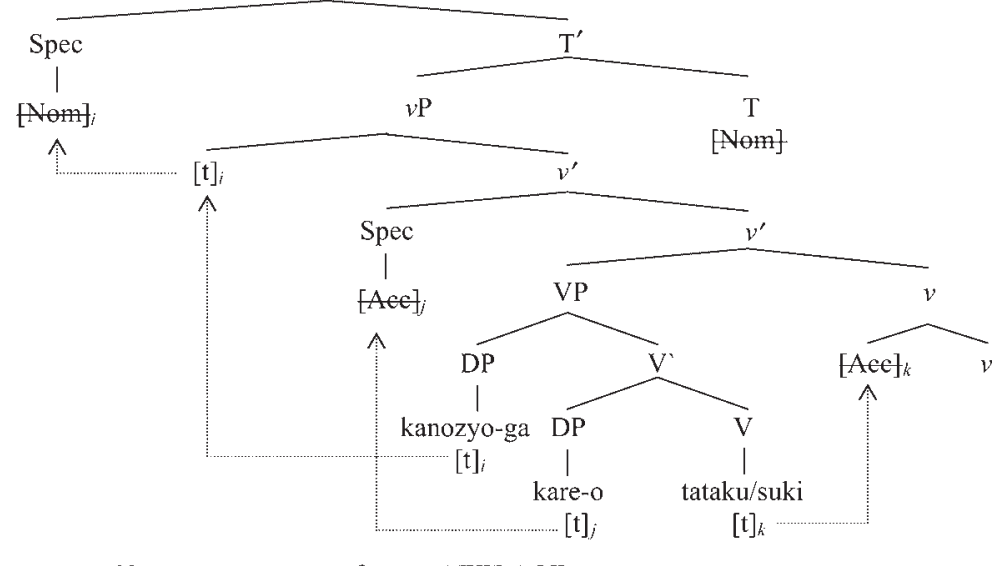

Note: $\longleftarrow \quad$ covert feature ATTRACT

The nominative Case of $\mathrm{T}$ is weak in Japanese as there is no subject-verb agreement and a subject does not raise overtly. ${ }^{5}$ The nominative Case of kanozyo-ga in (7) covertly moves to the specifier position of $\mathrm{T}$, and both Cases are checked off by the Spec-head relation in TP. The accusative Case of $\mathrm{V}$ is also weak in Japanese as there is no object-verb agreement. The accusative Case of kare-o covertly moves to the specifier position of $v$ and that of the verb tataku/suki also covertly moves to the head position of $v \mathrm{P}$ due to the affixal nature of $v$. Then, both Cases are eliminated by the Spec-head relation in $v \mathrm{P}$.

When stative verbs are used, and the subject and object are marked with the nominative case-marker $g a$ as in the case of (4b), another projection is required concerning Case checking. Following Chomsky

${ }^{5}$ There is an honorific feature, which requires a sort of subject-verb agreement in Japanese (Harada, 1976; Tateishi, 1991; Wakabayashi, 1997). This may suggest that Japanese has a form of subject-verb agreement in some cases. 
(1995), Koizumi (1995), and Ura (1996), we assume that multiple specifier positions of a single head are allowed as one aspect of parametric variation, and Japanese $\mathrm{T}$ is such a case. That is, the nominative Case of $\mathrm{T}$ has the ability to check off two (or more) nominative Cases, and two (or more) specifier positions are created in TP in Japanese as in (8). ${ }^{6}$

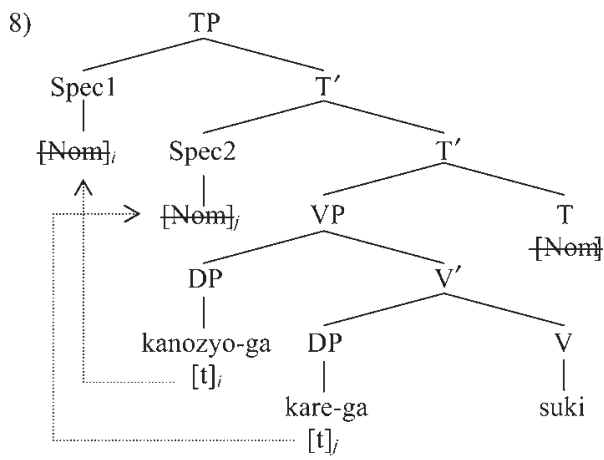

Note $\leqslant \ldots \ldots \ldots \ldots . .$. covert feature ATTRACT

The subject kanozyo-ga, the object kare-ga, and T have nominative Cases. Since the Case of T is weak in Japanese, both Cases of kanozyo$g a$ and kare-ga covertly raise to the specifier positions of $\mathrm{T}$ (Spec1 and Spec2), and they are eliminated by the Case of $\mathrm{T}$.

To sum up, when a subject is marked with the nominative case-marker $g a$ and an object is marked with the accusative case-marker $o$, the nominative Case of the subject moves to the specifier position of $\mathrm{T}$ and the accusative Case of the object moves to the specifier position of $v$. Then, the Case features are checked off in the relevant positions as in (7). When a subject and an object are marked with the nominative case-marker $g a$, their nominative Case features raise to their relevant specifier positions in TP. Subsequently, they are eliminated by the nominative Case feature of $\mathrm{T}$ as in (8). Hence, Case features are uniformly eliminated within the Spec-head relation in the specifier positions of the functional categories.

c Word order differences between Japanese and English: The canonical word order in Japanese is SOV, where the subject precedes the object.

${ }^{6}$ There is no light verb $v$ in (8). We assume that $v$ is included in the numeration only when it is required, and the accusative Case of the object is checked as in the case of (7). 
But Japanese also allows relatively free word orders. For instance, in (9a), the pronoun kare is marked with the nominative case-marker $g a$ and the pronoun kanozyo with the accusative case-marker $o$. This sentence yields an SOV word order. On the other hand, in (9b), kare is marked with the accusative case-marker $o$, and kanozyo with the nominative case-marker $g a$. Consequently, this sentence yields an OSV word order, which is also grammatical in Japanese. ${ }^{7}$

9) a. kare-ga kanozyo-o tataku he-Nom her-Acc hit 'He hits her.'

b. kare-o kanozyo-ga tataku him-Acc she-Nom hit 'She hits him.'

When different case-markers with non-stative verbs are used as in (9), no context is required to tell who did what since case-markers indicate the subject and object in the sentence. However, when both pronouns are marked with the nominative case-marker $g a$ with a stative verb, the situation is different. ${ }^{8}$ In this case, it is impossible to tell which pronoun is the subject and which is the object if a context is not given, as in (10).

10) kare-ga kanozyo-ga sukida he-Nom she-Nom like 'He likes her.' or 'She likes him.'

This sentence is ambiguous, and its English translation may be either He likes her or She likes him. This ambiguity will disappear when a context is given as in (11).

11) ${ }^{9}$ Taro-wa Hanako-o itumo mitumetei- masu. kurasu-no minna-wa Taro-Top Hanako-Acc always stare at-Mod class-in everyone-Top kare -ga kanozyo-ga sukida toiu koto-o sitte-imasu. he-Nom she-Nom like C Nominalizer-Acc know-Mod

'Taro is always staring at Hanako. Everyone in the class knows, "he likes her".'

In (11) the only felicitous interpretation of the underlined part is $\mathrm{He}$ likes her.

\footnotetext{
${ }^{7}$ The syntactic operation yielding this word order difference is called scrambling (see Saito, 1985). ${ }^{8} \mathrm{Japanese}$ has a topic-marker $w a$, and it is exceptional in colloquial speech for the nominative casemarker $g a$ to be used for both the subject and object, except when forced, as in the context given in the materials in this experiment.

${ }^{9}$-Top $=$ the topic-marker, - Mod $=$ modality.
} 


\section{Predictions of different models of SLA about case-marking in second language English}

In this section, we present three models of SLA and discuss their predictions concerning the acquisition of Case by JLEs.

\section{Full Transfer/Full Access model}

Schwartz (1998) and Schwartz \& Sprouse (1994; 1996; 2000) propose the Full Transfer/Full Access (FT/FA) model, where they claim that the final state of the first language (L1) grammar fully transfers to the initial state of the second language (L2) grammar, and that the L2 initial grammar will restructure where it cannot parse L2 input, under the constraints imposed by operations of UG. If this model is correct and the L1 grammar fully transfers to the L2 grammar, it is predicted that JLEs will use nominative forms in English in places where DPs are marked with the nominative case-marker $g a$, and accusative forms in English in places where DPs are marked with the accusative case-marker $o$. That is, when a subject is marked with the nominative case-marker $g a$ and an object is marked with the accusative case-marker $o$, JLEs will use sentences like (12a), and when both subject and object are marked with the nominative case-marker $g a$, they will use sentences as in (12b).

12) a. He hits/likes her.

b. * He likes she.

The sentence (12a) is allowed in English, but the sentence (12b) is not. The FT/FA will be regarded as correct if we find that JLEs accept sentences like (12b), where nominative pronominals are formed for both subject and object, since the double nominative construction is permitted in Japanese, but not in English.

Moreover, since Japanese allows OSV word order alongside canonical SOV, OVS sentences as in (13) will also be accepted by JLEs at a very early stage.

13) $<$ Object Verb Subject $>$

a. * Her hits/likes he.

b. * She likes he.

In addition, since the FT/FA claims that L2 learners acquire the L2 grammar by parameter (re)setting, it is predicted that JLEs will acquire the English Case system and accept English sentences where correct 


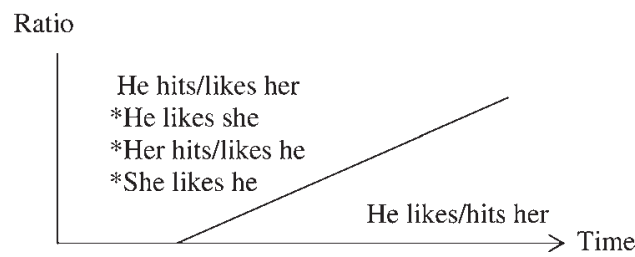

Figure 2 Predictions based on the FT/FA

word orders are used at some later stage. Figure 2 shows predicted development based on the FT/FA hypothesis.

\section{Minimal Trees model}

Vainikka and Young-Scholten $(1994 ; 1996 a ; 1996 b ; 1998)$ propose the Minimal Trees (MT) hypothesis, according to which only the headedness of VP is transferred at the initial stage of SLA, with other grammatical elements acquired as in L1 acquisition of the target language. If this model is correct and L2 learners transfer only the headedness of VP, it is predicted that JLEs will accept OVS sentences since Japanese is a head-final language, i.e. OV, and the specifier position would not be fixed at the early stage of SLA.

Concerning Case features, we assume that JLEs will make errors observed in the L1 acquisition of English. In studies of L1 acquisition, it has often been reported that children produce accusative forms for objects and accusative or nominative forms for subjects at an early stage as shown in (14), (15) and (16), respectively (see O'Grady, 1997).

14) a. Paula put them.

b. Pinch him.

c. Help me out.

15) a. Me got bean.

b. Her do that.

c. Him gone.

16) a. I got it.

b. She won't.

c. He's got.
(Paula: 18 months)

(Bethan: 21 months)

(Hayley: 20 months)

(Stefan: 17 months)

(Hayley: 20 months)

(Hayley: 20 months)

(Radford, 1990: 175-76)

(Angela: 25 months)

(Angela: 25 months)

(Angela: 25 months)
(Radford, 1990: 175)

(Aldridge, 1989: 181) 
If the MT hypothesis is applicable in this study and there are no functional categories such as $\mathrm{T}$ and $v$, which are checking domains for nominative Case and accusative Case features (Chomsky, 1995: 386, footnote 55), we assume that only VP is projected as in (17).

17) a.

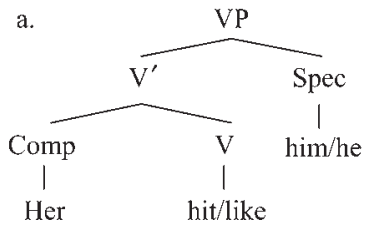

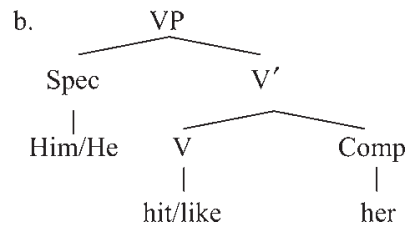

$\mathrm{T}$ is a checking domain for the nominative Case and $v$ is one for the accusative Case, but those domains do not exist in (17). The Case features of the subject and object cannot be checked properly, and the accusative form is used as the default form for the object and the accusative or nominative form is used as the unspecified form for the subject (Radford, 1990; Vainikka, 1993/94; Schütze and Wexler, 1996; Wexler, 1998; Ito, 2001). ${ }^{10}$

Thus if the MT hypothesis is correct, it is predicted that JLEs will accept English OVS sentences, where accusative and/or nominative forms are used for a subject and an accusative form is used for an object as in (18). Then, if JLEs acquire the headedness of VP in English properly, they will use the English word order SVO, but if they have not acquired functional properties, which check off Cases, then accusative or nominative pronouns for subjects and accusative pronouns for objects will be used as in (19).

18) <Object Verb Subject $>$

* Her hits/likes he/him.

19) $<$ Subject Verb Object $>$ He*Him hits/likes her.

In addition, since the MT hypothesis predicts that grammatical elements are acquired as in the L1 acquisition of the target language, it is predicted that JLEs will acquire functional properties and the English case system at some later stage. Figure 3 shows predictions of development based on MT.

\footnotetext{
${ }^{10}$ One reviewer observes that there should be some distinction between accusative forms in subject position and those in object position since the acquisition of object accusative forms occurs quite early. Further research will be required into this distinction, but we assume here that the accusative object is used as a default form and the accusative or nominative subject is used as an unspecified form.
} 


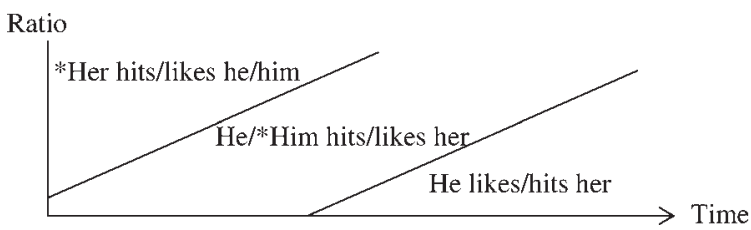

Figure 3 Predictions based on MT

\section{Lexical Learning/Lexical Transfer model}

Wakabayashi $(1997$; 2002) proposes the Lexical Learning/Lexical Transfer (LL/LT) model, where he claims that SLA results from lexical learning as in L1 acquisition (see Clahsen et al., 1994; 1996) and an L2 lexicon is newly built either by learning features of lexical items from scratch from L2 input or by transferring features of L1 lexical items. This model assumes the following developmental sequences in SLA.

20) a. [ VP ]

b. $[v \mathrm{P}[\mathrm{VP}]]$

c. $[\mathrm{TP}[v \mathrm{P}[\mathrm{VP}]]]$

The first property acquired is the lexical head $\mathrm{V}$ as in (20a). The second property acquired is $v$ as in (20b), whether $v$ is an L2 lexical item (by lexical learning) or an L1 lexical item (by L1 transfer). The third property acquired is $\mathrm{T}$ as in (20c), whether $\mathrm{T}$ is an L2 lexical item or an L1 lexical item.

According to this model, JLEs will start to acquire English as it is acquired in L1 acquisition, and they will also apply Japanese to English during the course of lexical learning. Hence, it is predicted that JLEs will accept English sentences as in (18) and (19) at an early stage, and after they acquire head features and complement features, they will use the correct English word order as in (19). Then, they will make use of the Japanese case system in English by L1 transfer as in (12), and nominative objects will appear when stative verbs are used. Figure 4 illustrates predictions of development based on the LL/LT.

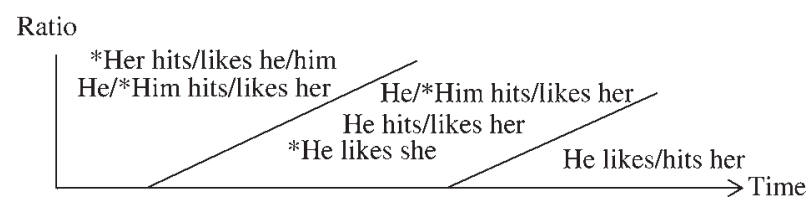

Figure 4 Predictions based on the LL/LT 
As demonstrated above, FT/FA, MT and LL/LT make distinct predictions. We will test these predictions against data in the following sections.

\section{Experiment}

\section{Participants}

The study was conducted with the participation of seventh- and eighthgrade students in Japan. All had received normal school education in Japan, based on a structural syllabus in which pattern practice was very common. They had English lessons no more than a few hours a week. There were three groups of JLEs in this experiment. Group 1 was comprised of seventh-graders (age 12-13) and the minimum amount of exposure to English was 6 months. They were almost complete beginners, but they had received 8 lessons focusing specifically on morphological case-marking of English pronouns in a private supplemental school in Japan just before their participation in this experiment. In these lessons, they had been taught the inflectional paradigm of pronominal case-marking, and they had also practised translation between Japanese and English emphasizing pronominal forms during the lessons. They were tested on their memorization of the paradigm a few times and showed that they could fill in the paradigm without error. We assume that they had learned the pronominal forms and their meanings correctly. Group 2 was also seventh-graders but their minimum exposure to English was 9 months. They had studied the morphological case-marking of pronouns for 3 months through explicit grammar teaching prior to the experiment. The JLEs in Groups 1 and 2 had learned subject-verb agreement for be-verbs such as is, am and are, but a crucial difference between the groups is that the JLEs in Group 1 had not received instruction on subject-verb agreement on lexical verbs with respect to third person singular present tense forms. Group 3 was comprised of eighth-graders (age 13-14) and their minimum exposure to English was 21 months. ${ }^{11}$ They had already learned subject-verb agreement on $b e$-verbs and lexical verbs.

\footnotetext{
${ }^{11}$ As a Second Language Research reviewer pointed out, the intervals between the Groups were not consistent: 3 months between Groups 1 and 2, and 12 months between Groups 2 and 3. What we wanted to see in this study was how JLEs constructed their interlanguage grammars in a very early period (by examining the data of Group 1) and how their interlanguage grammars change in the course of the acquisition (by Examining the data of Groups 2 and 3). In this sense, the length of intervals between groups may be irrelevant, because developmental changes are very unlikely to take place in accordance with the duration of learning (e.g. one change every three weeks).
} 
The participants were selected on the basis of sensitivity to casemarking in Japanese as measured by a pretest. ${ }^{12}$ The pretest involved contexts like that in (11), repeated here as (21):

21) Taro-wa Hanako-o itumo mitumetei-masu. kurasu-no minna-wa

Taro-Top Hanako-Acc always stare-at-Mod class-in everyone-Top

kare-ga kanozyo-ga sukida toiu koto-o sitteimasu.

he-Nom she-Nom like $\mathrm{C}$ Nominalizer-Acc know

'Taro is always staring at Hanako. Everyone in the class knows, "he likes her".'

Each context was followed by a question, and a set of possible answers as in 22):

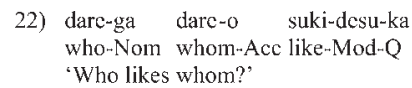

( $\left.\begin{array}{l}\text { kare-ga } \\ \text { he-Nom } \\ \text { kanozyo-ga } \\ \text { she-Nom } \\ \text { sonota-ga } \\ \text { someone else-Nom }\end{array}\right]\left[\begin{array}{l}\text { kanozyo-o } \\ \text { her-Acc } \\ \text { karc-o } \\ \text { him-Acc } \\ \text { sonota-o } \\ \text { someone else-Acc }\end{array}\right]$ suki-desu.

Participants were asked to select one participant from column 1 and one from column 2 appropriate to the interpretation of (21). In this case, they should select kare-ga from the first column and kanozyo-o from the second. Only those informants who correctly answered all questions were retained for analysis in the main task, since they were considered to have appropriately understood the interaction between case-marking and word order in Japanese sentences. This produced 3 experimental groups, as illustrated in Table 1:

\section{Procedure}

Participants were given Japanese contexts identical to those used in the pretest, as illustrated in (21). The embedded target sentences were of three types:

Table 1 Participant details

\begin{tabular}{lll}
\hline Group & Number & The minimum amount of exposure to English \\
\hline Group 1 & 22 & 6 months (pronouns were introduced 1 month ago) \\
Group 2 & 28 & 9 months (pronouns were introduced 3 months ago) \\
Group 3 & 31 & 21 months (pronouns were introduced 15 months ago) \\
\hline
\end{tabular}

\footnotetext{
${ }^{12}$ Native English speakers were not involved as a control group for two reasons: the task required knowledge of Japanese; and the grammaticality of the target sentences was so clear that we did not need to refer to native speakers' judgements.
} 
23) Type $1<$ Sub-ga Obj-o Non-Stative Verb $>$

a. kanozyo-ga kare-o sonkeisuru she-Nom him-Acc respect

'She respects him.'

Type $2<$ Sub-ga Obj-o Stative Verb $>$

b. kanozyo-ga kare-o sukida she-Nom him-Acc like

'She likes him.'

Type $3<$ Sub-ga Obj-ga Stative Verb $>$

c. kare-ga kanozyo-ga sukida

he-Nom she-Nom like

'He likes her.'

Type 1 was the Sub-ga Obj-o Non-Stative Verb construction, where the subject was marked with the nominative case-marker $g a$, and the object with the accusative case-marker $o$. Three non-stative verbs, sonkeisuru 'respect', homeru 'praise' and keru 'kick', were used. ${ }^{13}$ Type 2 was the Sub-ga Obj-o Stative Verb construction, where the subject was marked with the nominative case-marker $g a$, and the object by the accusative case-marker $o$. Three stative verbs, sukida 'like', nikui 'hate' and hituyooda 'need', were used. ${ }^{14}$ Type 3 was the Sub-ga Obj-ga Stative Verb construction, where the subject was marked with the nominative case-marker $g a$, and the object also by the nominative case-marker $g a$. As explained earlier, this double nominative construction is allowed only when stative verbs are used. Stative verbs in Type 3 were identical to those in Type 2. Moreover, four types of pronouns, watasi (first person singular), watasitati (first person plural), kare and kanozyo, were used. Each type had 3 tokens, so 9 tokens were given in total. ${ }^{15}$

\footnotetext{
${ }^{13}$ For participants in Groups 2 and 3, tataku 'hit' was used instead of keru 'kick'. This had no substantive effect on the results.

${ }^{14}$ For participants in Groups 2 and 3, kirai 'dislike' was used instead of nikui 'hate'. This had no substantive effect on the results.

${ }^{15} \mathrm{~A}$ Second Language Research reviewer suggested that verbs considered here as non-stative verbs in English such as sonkeisuru 'respect', homeru 'praise' and keru 'kick' are quite heterogeneous. These verbs were chosen because of their object case-marking properties in Japanese. What we wanted to examine in this study was whether object case-marking in Japanese was transferred or not. Even though the non-stative category was diverse and/or several types of pronominals were used, repeated-measures ANOVAs indicated no differences among sentences in the pretest (Group 1: Type $1\left(F_{2,14}=0.04\right.$, not significant, or n.s.), Type $2\left(F_{2,14}=0.2\right.$, not significant, or n.s.), Type $3\left(F_{2}\right.$ ${ }_{14}=0.02$, not significant, or n.s.), Group 2: Type $1\left(F_{2,14}=0.03\right.$, not significant, or n.s.), Type 2 $\left(F_{2,14}=0\right.$, not significant, or n.s.), Type 3 ( $F_{2,14}=0.23$, not significant, or n.s.), Group 3: Type 1 $\left(F_{2,14}=0\right.$, not significant, or n.s.), Type $2\left(F_{2,14}=0\right.$, not significant, or n.s. $)$, Type $3\left(F_{2,14}=0.03\right.$, not significant, or n.s.)). Hence, it is safe to assume that differences between first person and third person, between singular and plural, and among verbs had no effect on the interpretation of the sentences (i.e. which is the experiencer (or agent) and which is the theme).
} 
In contrast to the pretest, where each item was followed by a question in Japanese, for the main test, each item was followed by 8 possible English translations of the target sentence, as illustrated in (24):

24) Taro-wa Hanako-o itumo mitumetei-masu. kurasu-no minna-wa Taro-Top Hanako-Acc always stare at-Mod class-in everyone-Top

$\begin{array}{llllll}\text { kare-ga } & \text { kanozyo-ga } & \text { sukida } & \text { toiu } & \text { koto-o } & \text { sitte-imasu. } \\ \text { he-Nom } & \text { she-Nom } & \text { like } & \text { C } & \text { Nominalizer-Acc } & \text { know-Mod }\end{array}$

'Taro is always staring at Hanko. Everyone in the class knows. "he likes her".'

( )a. He likes she. ( )b. He likes her. ( )c. Him likes she. ( )d.Him likes her.

( )e. She likes he. ( )f. She likes hi,. ( )g. Her likes he. ( )h. Her likes him.

Participants were asked to indicate whether each choice could be the translation equivalent of the underlined part:

- Choice (a) had both the subject and object in the nominative forms: $\mathrm{Sub}(\mathrm{Nom}) / \mathrm{Obj}(\mathrm{Nom})$.

- Choice (b) had the subject in the nominative form and the object in the accusative form: $\mathrm{Sub}(\mathrm{Nom}) / \mathrm{Obj}$ (Acc).

- Choice (c) had the subject in the accusative form and the object in the nominative form: $\mathrm{Sub}(\mathrm{Acc}) / \mathrm{Obj}(\mathrm{Nom})$.

- Choice (d) had both the subject and object in the accusative form: Sub(Acc)/Obj(Acc).

- Choices (e), (f), (g) and (h) were inversions of (a), (b), (c) and (d).

The choices were randomly ordered in the experiment. Participants read Japanese sentences and at the same time listened to a tape, where the same Japanese sentences and English choices were recorded. ${ }^{16}$ They were asked to mark correct translations with a circle $(O)$ and incorrect translations with a cross $(\times)$. They could write a question mark (?) when they were not sure. They were also told that they could mark more than one choice if needed for each item. Two practice items were given at the beginning with the instructions. After this practice, the experimenter made sure that participants knew how to respond.

\footnotetext{
${ }^{16}$ There were two main reasons for using two modalities: the written material and the tape. If we had used only written material, learners might have used meta-linguistic knowledge because of the lack of a time constraint, and if we had used only the tape, they might not have properly understood the English sentences since they were beginners; see also Dube, 2000.
} 


\section{Results}

The overall results are presented first, followed by discussion of particular choices and individual participant results.

\section{Group data}

Acceptance rates: Results are reported in percent acceptance by participants in each group, as in Table 2. In Group 1, when Type 1 (the Sub-ga Obj-o Non-Stative Verb construction) and Type 2 (the Sub-ga Obj-o Stative Verb construction) were presented, participants accepted $\mathrm{Sub}(\mathrm{Nom}) / \mathrm{Obj}$ (Acc) at rates of $61 \%$ and $62 \%$. When Type 3 sentences (the Sub-ga Obj-ga Stative Verb construction) were given, they accepted both the $\mathrm{Sub}(\mathrm{Nom}) / \mathrm{Obj}(\mathrm{Nom})$ and the $\mathrm{Sub}(\mathrm{Acc}) / \mathrm{Obj}(\mathrm{Acc})$ constructions at $49 \%$. Repeated-measured ANOVAs showed that there were highly significant differences between the English choices for each Japanese sentence type (Type 1: $\mathrm{F}_{7,14}=30.62, \quad p<0.01$; Type 2: $\mathrm{F}_{7,14}=20.36, p<0.01$; and Type 3: $\left.\mathrm{F}_{7,14}=22.8, p<0.01\right)$. In Group 2, participants accepted $\mathrm{Sub}(\mathrm{Nom}) / \mathrm{Obj}$ (Acc) for Type 1 at 50\%; they accepted $\mathrm{Sub}(\mathrm{Nom}) / \mathrm{Obj}$ (Acc) for Type 2 at $65 \%$; and for Type 3, they accepted $\mathrm{Sub}(\mathrm{Nom}) / \mathrm{Obj}(\mathrm{Nom})$ at $49 \%$ and $\mathrm{Sub}(\mathrm{Nom}) / \mathrm{Obj}(\mathrm{Acc})$ at $50 \%$. Repeatedmeasured ANOVAs again showed that there were highly significant differences between the English choices in each Japanese sentence type (Type 1: $\mathrm{F}_{7,14}=7.98, p<0.01$; Type $2: \mathrm{F}_{7,14}=12.72, p<0.01$; and Type 3: $\left.\mathrm{F}_{7,14}=10.36, p<0.01\right)$. In Group 3, when Type 1 and Type 2 were given, a correct English choice, namely $\mathrm{Sub}(\mathrm{Nom}) / \mathrm{Obj}(\mathrm{Acc})$, was accepted at $75 \%$ and $77 \%$, and for Type 3, participants accepted Sub(Nom)/Obj(Nom) at $41 \%$ and $\mathrm{Sub}(\mathrm{Nom}) / \mathrm{Obj}$ (Acc) at $58 \%$. Repeated-measured ANOVAs showed that there were highly significant differences between English choices for each Japanese sentence type (Type 1: $\mathrm{F}_{7,14}=90.69, p<0.01$; Type 2: $\mathrm{F}_{7,14}=83.23, p<0.01$; and Type 3: $\mathrm{F}_{7,14}=33.6, p<0.01$ ).

Although 8 English choices were given in each trial only three choices - namely $\mathrm{Sub}(\mathrm{Nom}) / \mathrm{Obj}(\mathrm{Nom}), \operatorname{Sub}(\mathrm{Nom}) / \mathrm{Obj}(\mathrm{Acc})$ and $\mathrm{Sub}(\mathrm{Acc}) / \mathrm{Obj}(\mathrm{Acc})$ - were accepted at more than $40 \%$ by one (or more) of the groups. Sub(Nom)/Obj(Nom) was accepted frequently by all groups with Type 3 (stative) verbs. Sub(Nom)/Obj(Acc) was regarded as correct much more frequently than other choices by all Groups, and $\mathrm{Sub}(\mathrm{Acc}) / \mathrm{Obj}(\mathrm{Acc})$ was allowed by Group 1 in particular. Dealing with 


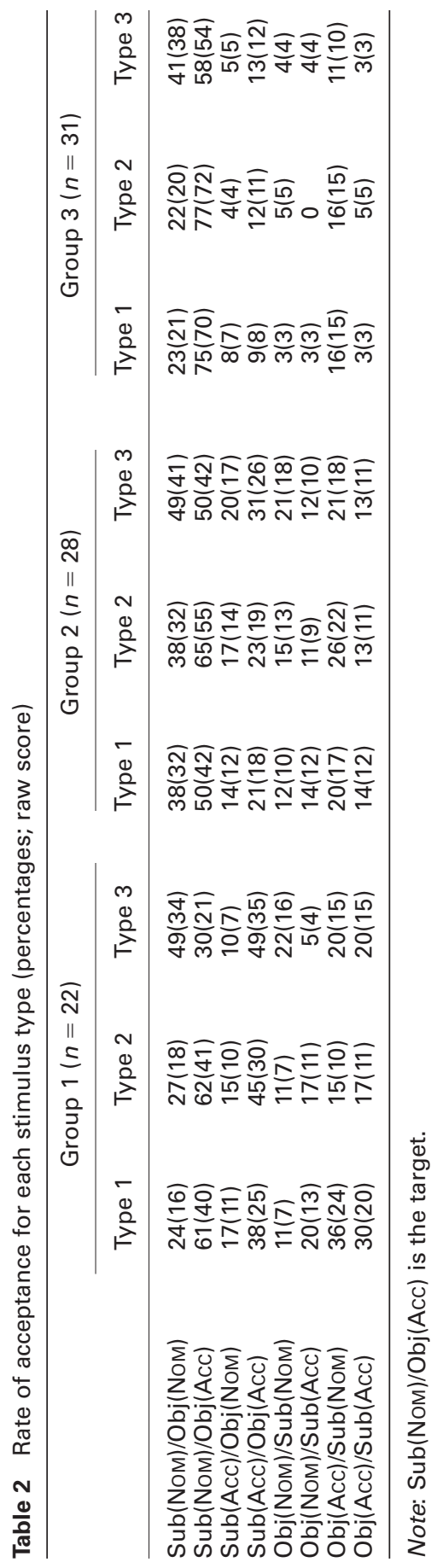


only these three English choices, we can examine the compatibility of the results with the three SLA models, since each model makes different predictions as discussed in the previous section. To do this, we first examine cross-sectional group data.

\section{Cross-sectional differences among the groups}

Figures 5, 6, 7 show response rates to different Japanese sentence types. For Type 1 (the Sub-ga Obj-o Non-Stative Verb construction), we find the following tendencies.

25) a. $\mathrm{Sub}(\mathrm{Nom}) / \mathrm{Obj}(\mathrm{Nom})$ was accepted by Group $2\left(\mathrm{~F}_{2,6}=8.74, p<0.05\right)$.

b. $\mathrm{Sub}(\mathrm{Nom}) / \mathrm{Obj}(\mathrm{Acc})$ was accepted by Group $3\left(\mathrm{~F}_{2,6}=10.96, p<0.01\right)$.

c. $\mathrm{Sub}(\mathrm{Acc}) / \mathrm{Obj}(\mathrm{Acc})$ was accepted by Groups $1 \& 2\left(\mathrm{~F}_{2,6}=27.38, p<0.01\right)$.

For Type 2 (the Sub-ga Obj-o Stative Verb construction), we find the following tendencies.

26) a. $\operatorname{Sub}(\mathrm{Nom}) / \mathrm{Obj}(\mathrm{Acc})$ was accepted by Group $2\left(\mathrm{~F}_{2,6}=14.16, p<0.01\right)$.

b. $\mathrm{Sub}(\mathrm{Acc}) / \mathrm{Obj}(\mathrm{Acc})$ was accepted by Group 1 more frequently than Group $3\left(\mathrm{~F}_{2,6}=8.53, p<0.05\right)$.

For Type 3 (the Sub-ga Obj-ga Stative Verb construction), we find the following tendencies.

27) a. $\mathrm{Sub}(\mathrm{Nom}) / \mathrm{Obj}(\mathrm{Acc})$ was accepted by Groups $2 \& 3\left(\mathrm{~F}_{2,6}=18.6, p<0.01\right)$.

b. $\mathrm{Sub}(\mathrm{Acc}) / \mathrm{Obj}(\mathrm{Acc})$ was accepted by Group $1\left(\mathrm{~F}_{2,6}=27.38, p<0.01\right)$.

\section{Group data from selected participants}

As seen in the previous section, a number of participants judged more than two English choices as correct or were uncertain about them. Since it is difficult to identify clear tendencies or discuss the JLEs' interlanguage grammars from this kind of data, participants who made more than two choices are excluded from further analysis. The numbers of participants in each group examined throughout the remainder of the study are given in Table 3 .

a Acceptance rates: Looking at the overall data from the selected participants, Table 4 shows the rates at which they judged the English options as correct for each Japanese sentence type. 


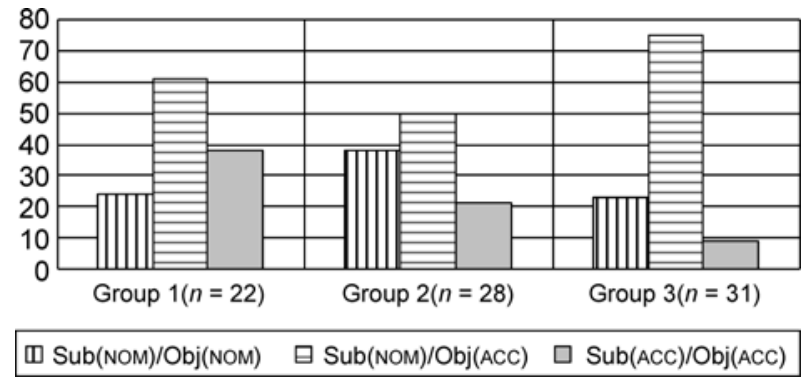

Figure 5 Cross-sectional differences for the Subj-ga Obj-o Non-Stative Verb

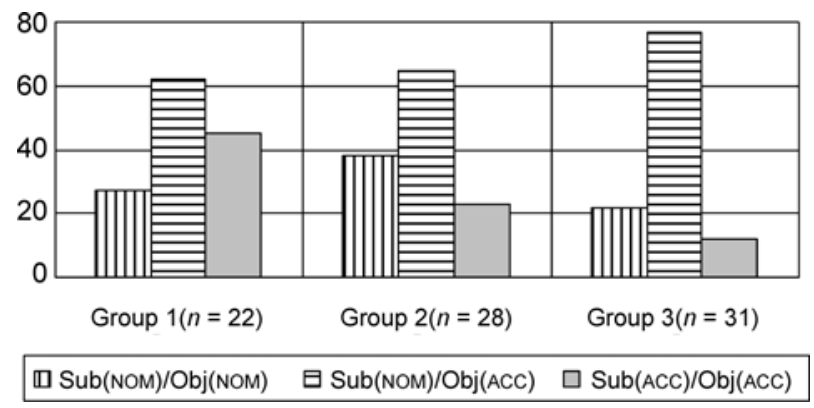

Figure 6 Cross-sectional differences for the Subj-ga Obj-o Stative Verb

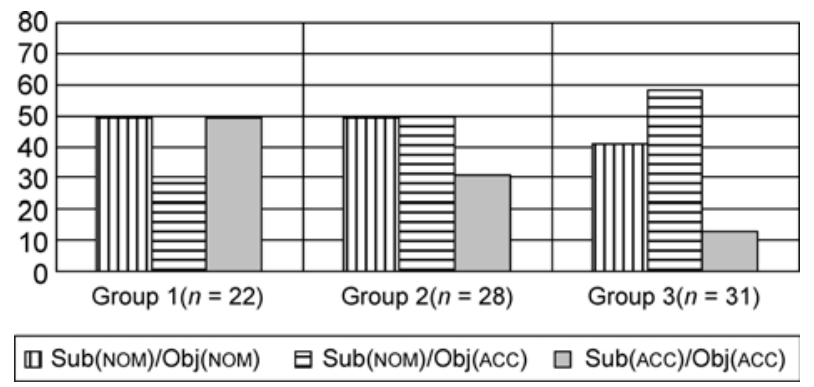

Figure 7 Cross-sectional differences for the Sub-ga Obj-ga Stative Verb

Table 3 The number of participants remained for further analysis

\begin{tabular}{lcl}
\hline Group & Number & The minimum amount of exposure to English \\
\hline Group 1 & 9 & 6 months (pronouns were taught 1 month ago) \\
Group 2 & 8 & 9 months (pronouns were taught 3 months ago) \\
Group 3 & 15 & 21 months (pronouns were taught 15 months ago) \\
\hline
\end{tabular}

b Individual data: Next, consider data from individual participants. Following the analyses in Thomas (1991), participants were considered to be consistent if they accepted one choice - e.g. Sub(Nom)/ 


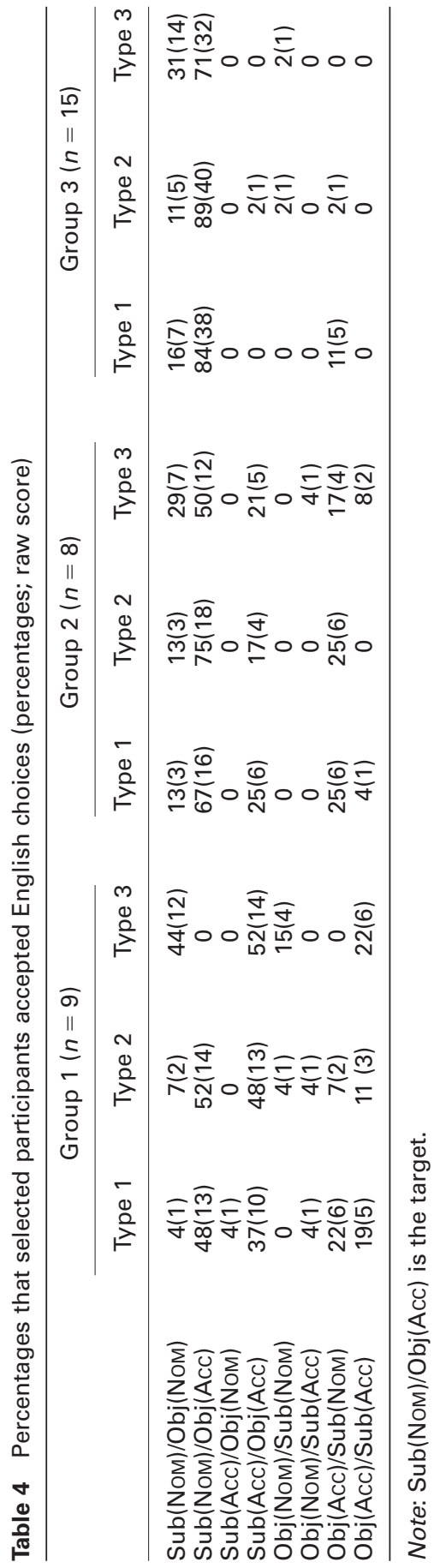


Obj(Nom) - for at least two of the three tokens of a construction type (e.g. Sub-ga Obj-ga Stative Verb). With this criterion, 5 patterns were found among a number of participants. These patterns are presented in Table 5.

In Pattern 1, both $\mathrm{Sub}(\mathrm{Acc}) / \mathrm{Obj}(\mathrm{Acc})$ and $\mathrm{Obj}(\mathrm{Acc}) / \mathrm{Sub}(\mathrm{Acc})$ were accepted for all three types of Japanese sentences. In Pattern 2, $\mathrm{Sub}$ (Acc)/Obj(Acc) was accepted for all Japanese sentence types. In Pattern 3, Sub(Nom)/Obj(Acc) was accepted when the subject was marked with the nominative case-marker $g a$ and the object was marked with the accusative case-marker $o$ (Types 1 and 2), and $\mathrm{Sub}(\mathrm{Nom}) / \mathrm{Obj}(\mathrm{Nom})$ was accepted when both subject and object were marked with the nominative case-marker ga (Type 3). In Pattern 4, Sub(Nom)/Obj(Nom) was accepted for all Japanese sentence types. In Pattern 5, a correct English choice $\mathrm{Sub}(\mathrm{Nom}) / \mathrm{Obj}$ (Acc) was accepted for all Japanese sentences.

The number of participants in each Pattern is shown in Table 6.

Two participants in Group 1 accepted Sub(Acc)/Obj(Acc) and Obj(Acc)/Sub(Acc) for all Japanese sentences (Pattern 1). Two participants in Group 1 and two in Group 2 accepted Sub(Acc)/Obj(Acc) (Pattern 2). Four participants in Group 1, two in Group 2 and three in Group 3 accepted $\mathrm{Sub}(\mathrm{Nom}) / \mathrm{Obj}(\mathrm{Acc})$ when the object was marked with the accusative case-marker $o$ and $\mathrm{Sub}(\mathrm{Nom}) / \mathrm{Obj}(\mathrm{Nom})$ when the object was marked with the nominative case-marker $g a$ (Pattern 3). One participant in Group 2 and one in Group 3 accepted Sub(Nom)/Obj

Table 5 Summary of patterns

\begin{tabular}{|c|c|c|}
\hline Pattern & Japanese sentence types & English choices \\
\hline Pattern 1 & $\begin{array}{l}\text { Subj-ga Obj-o Non-Stative Verb } \\
\text { Subj-ga Obj-o Stative Verb } \\
\text { Subj-ga Obj-ga Stative Verb }\end{array}$ & $\begin{array}{l}\operatorname{Sub}(A c c) / O b j(A c c) \\
\& \\
\text { Obj(Acc)/Sub(Acc) }\end{array}$ \\
\hline Pattern 2 & $\begin{array}{l}\text { Subj-ga Obj-o Non-Stative Verb } \\
\text { Subj-ga Obj-o Stative Verb } \\
\text { Subj-ga Obj-ga Stative Verb }\end{array}$ & $\operatorname{Sub}(A c c) / O b j(A c c)$ \\
\hline Pattern 3 & $\begin{array}{l}\text { Subj-ga Obj-o Non-Stative Verb } \\
\text { Subj-ga Obj-o Stative Verb } \\
\text { Subj-ga Obj-ga Stative Verb }\end{array}$ & $\begin{array}{l}\text { Sub(Nom)/Obj(Acc) } \\
\text { Sub(Nom)/Obj(Nom) }\end{array}$ \\
\hline Pattern 4 & $\begin{array}{l}\text { Subj-ga Obj-o Non-Stative Verb } \\
\text { Subj-ga Obj-o Stative Verb } \\
\text { Subj-ga Obj-ga Stative Verb }\end{array}$ & Sub(Nom)/Obj(Nom) \\
\hline Pattern 5 & $\begin{array}{l}\text { Subj-ga Obj-o Non-Stative Verb } \\
\text { Subj-ga Obj-o Stative Verb } \\
\text { Subj-ga Obj-ga Stative Verb }\end{array}$ & Sub(Nom)/Obj(Acc) \\
\hline
\end{tabular}

Note: Pattern 5 was the correct choice. 
Table 6 The number in each pattern

\begin{tabular}{llllc}
\hline & Pattern & $\begin{array}{l}\text { Group 1 } \\
(n=9)\end{array}$ & $\begin{array}{l}\text { Group 2 } \\
(n=8)\end{array}$ & $\begin{array}{l}\text { Group 3 } \\
(n=15)\end{array}$ \\
\hline Pattern 1 & $\begin{array}{l}\text { Sub(Acc)/Obj(Acc) for all Types } \\
\text { Obj(Acc)/Sub(Acc) for all Types }\end{array}$ & 2 & 0 & 0 \\
Pattern 2 & Sub(Acc)/Obj(Acc) for all Types & 2 & 2 & 0 \\
Pattern 3 & Sub(Nom)/Obj(Acc) for Type 1 and 2 & 4 & 2 & 3 \\
& Sub(Nom)/Obj(Nom) for Type 3 & & & \\
Pattern 4 & Sub(Nom)/Obj(Nom) for allTypes & 0 & 1 & 1 \\
Pattern 5 & Sub(Nom)/Obj(Acc) for all Types & 0 & 2 & 10 \\
Others & & 1 & 1 & 1 \\
\hline
\end{tabular}

Note: Pattern 5 was the correct choice.

(Nom) (Pattern 4). Two participants in Group 2 and 10 in Group 3 accepted only correct English choices, namely Sub(Nom)/Obj(Acc) (Pattern 5). One participant in each Group showed other patterns, which were not identical to the above patterns.

\section{Discussion}

It was observed from the overall data in Table 2 that participants accepted three English constructions, namely Sub(Nom)/Obj(Nom), Sub(Nom)/ Obj (Acc) and $\mathrm{Sub}$ (Acc)/Obj(Acc), at more than 50\%. Then focusing on those three choices, we examined cross-sectional data between Groups (Figures 5, 6 and 7). The cross-sectional data indicated that Group 1 tended to accept Sub(Acc)/Obj(Acc), Group 2 accepted Sub(Nom)/Obj(Nom) and $\mathrm{Sub}(\mathrm{Nom}) / \mathrm{Obj}$ (Acc), and Group 3 accepted Sub(Nom)/Obj(Acc). In addition, we investigated other types of data from 32 selected participants who showed clear tendencies in their judgements.

Looking at data from individual participants, we found 5 patterns in which participants consistently chose one English option. If JLEs accepted the English options at random, such patterns would not be found. Moreover, some patterns were found among participants in all groups, and changes in patterns likely reflect the development of interlanguage grammars. In the following section, we focus on response patterns among those participants who exhibited consistent behaviour and we posit syntactic projections to generate each pattern couched in the framework of the Minimalist Program (Chomsky, 1995). Finally, we examine the validity of the three SLA models based on our predictions in Section III. 


\section{Syntactic projections in JLEs' grammars}

A summary of the 5 patterns observed among the selected participants appears in (28).

28) a. Pattern 1: $\mathrm{Sub}(\mathrm{Acc}) / \mathrm{Obj}(\mathrm{Acc})$ and $\mathrm{Obj}(\mathrm{Acc}) / \mathrm{Sub}(\mathrm{Acc})$ were accepted.

b. Pattern 2: $\mathrm{Sub}(\mathrm{Acc}) / \mathrm{Obj}(\mathrm{Acc})$ was accepted.

c. Pattern 3: $\mathrm{Sub}(\mathrm{Nom}) / \mathrm{Obj}(\mathrm{Acc})$ was accepted when the object was marked with the accusative case-marker $o$, and $\mathrm{Sub}(\mathrm{Nom}) / \mathrm{Obj}(\mathrm{Nom})$ was accepted when the object was marked with the nominative case-marker $g a$.

d. Pattern 4: Sub(Nom)/Obj(Nom) was accepted.

e. Pattern 5: Sub(Nom)/Obj(Acc) was accepted.

a Structure of Pattern 1: Participants whose responses exhibited Pattern 1 accepted $\mathrm{Sub}(\mathrm{Acc}) / \mathrm{Obj}(\mathrm{Acc})$ and $\mathrm{Obj}(\mathrm{Acc}) / \mathrm{Sub}(\mathrm{Acc})$ for all Japanese sentence types. With respect to word order, we propose that they accepted OVS patterns because of L1 transfer. As we saw in (10), Japanese allows a number of word orders, including both SVO and OVS. Both orders are structured by adjunction operations. With respect to the use of the accusative pronoun, we assume that accusative forms are default, because no syntactic operation is given to check Cases on the pronouns. That is, the participants had not taken functional categories such as $v$ and $\mathrm{T}$ (and their features) into the numeration yet. The structures for these types are given in (29).

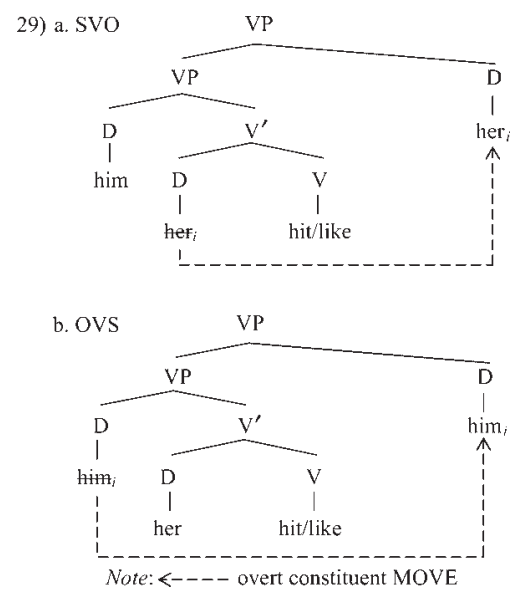

In child L1 acquisition, it is often proposed that there is a VP stage in which functional categories such as $\mathrm{T}$ and $\mathrm{C}$ do not exist (Radford, 1990; Vainikka, 1993/94). If this idea is applied to SLA, the structure (29) is comparable with child grammar. 


\section{The acquisition of pronominal case-marking}

$b$ Structure of Pattern 2: Participants whose responses exhibited Pattern 2 accepted $\mathrm{Sub}(\mathrm{Acc}) / \mathrm{Obj}(\mathrm{Acc})$ for all Japanese sentence types. We assume that, unlike participants in Pattern 1, they had already acquired the headedness of VP in English, although they had not yet acquired functional properties. Therefore, the double object construction was observed. Whether the adjunction operation in (29) has disappeared remains an unanswered question as we have no data to address this.

c Structure of Pattern 3: Participants with Pattern 3 accepted $\mathrm{Sub}$ (Nom)/Obj(Acc) when the object was marked with the accusative case-marker $o$ (Type 1 and 2) and $\mathrm{Sub}(\mathrm{Nom}) / \mathrm{Obj}(\mathrm{Nom})$ when the object was marked with the nominative case-marker ga (Type 3). Apparently, they had replaced the pronoun marked with the nominative case-marker $g a$ by the nominative pronoun in English and the pronoun marked with the accusative case-marker $o$ by the accusative pronoun in English. Hence they appear to have transferred, with the exception of the headedness, all L1 properties, such as the [stative/non-stative] feature of $\mathrm{V}$, a light verb $v$ to check the accusative Case and $\mathrm{T}$ to check the nominative Case. ${ }^{17,18}$ When $\mathrm{Sub}(\mathrm{Nom}) / \mathrm{Obj}(\mathrm{Acc})$ was accepted, the syntactic projection can be illustrated as in (30).

30)

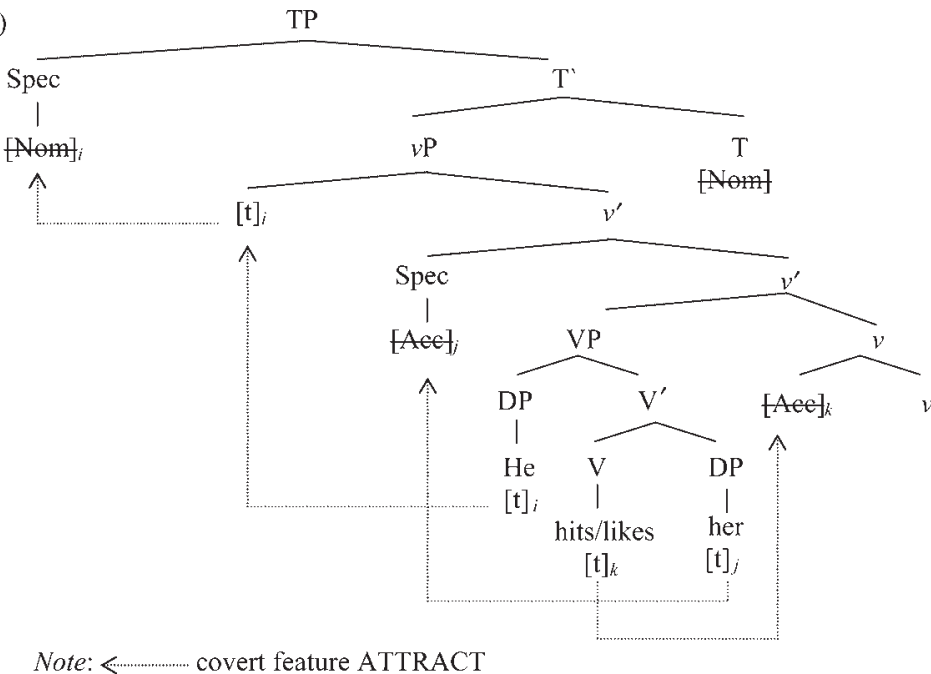

\footnotetext{
${ }^{17}$ It is possible to argue that a light verb $v$ in English was acquired. The role of $v$ in English is very similar to that in Japanese because in both languages it requires covert raising of the accusative Case feature. ${ }^{18} \mathrm{We}$ assume that the use of the nominative pronouns in the subject position and of the double nominative construction are evidence for the existence of $\mathrm{T}$ in these participants' grammars.
} 
We assume that $\mathrm{V}, v$ and $\mathrm{T}$ in Japanese were included in the numeration when $\mathrm{Sub}$ (Nom)/Obj(Acc) was accepted, and that the structure (30) was projected. In the derivation, the nominative Case of the subject $H e$ moves to the specifier position of $\mathrm{T}$ and the nominative Cases of the subject and $\mathrm{T}$ are checked off. The accusative Case of the object her raises to the specifier position of $v$ and the accusative Cases of the object and $v$ are eliminated.

As for the acceptability of $\mathrm{Sub}(\mathrm{Nom}) / \mathrm{Obj}(\mathrm{Nom})$, the syntactic projection can be shown in (31).

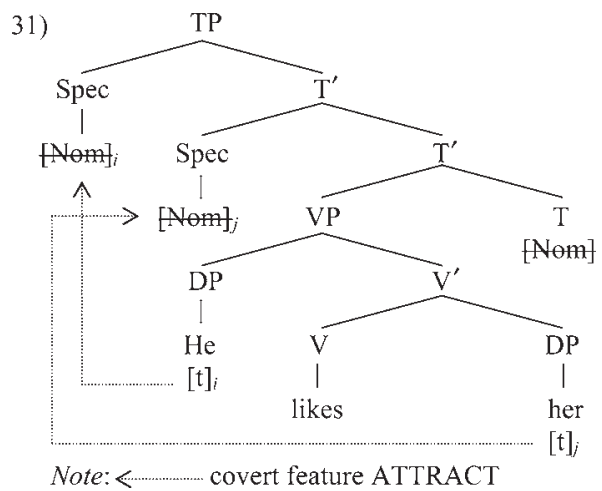

In this case, $\mathrm{T}$ and $\mathrm{V}$ should be included in the numeration. In Japanese, $\mathrm{T}$ can have two specifier positions and have the ability to check off two (or more) nominative Cases, and the double nominative construction is allowed (see Ura, 1996). The nominative Cases of the subject and object move to specifier positions of $\mathrm{T}$, and they are eliminated by the nominative Case of $\mathrm{T}$ as in (31). Thus, we suggest that the participants with Pattern 3 had transferred those lexical items directly from Japanese.

d Structure of Pattern 4: Participants whose responses exhibited Pattern 4 accepted $\mathrm{Sub}(\mathrm{Nom}) / \mathrm{Obj}(\mathrm{Nom})$ for all Japanese sentence types. As explained with reference to (31) above, the nominative Case of $\mathrm{T}$ in Japanese may have two (ore more) specifier positions and hence Japanese allows the double nominative construction (see Ura, 1996). We propose that these participants had transferred the Case from Japanese and generalized that it could be used in all sentences.

e Structure of Pattern 5: Participants with Pattern 5 accepted $\mathrm{Sub}(\mathrm{Nom}) / \mathrm{Obj}$ (Acc) for all Japanese sentence types. We suggest that 
they have acquired $\mathrm{V}, v$ and $\mathrm{T}$ of English since there was no influence of Japanese. In the numeration, these lexical items were included, but features associated with corresponding Japanese lexical items were not taken into the numeration. The syntactic object is illustrated in (32).

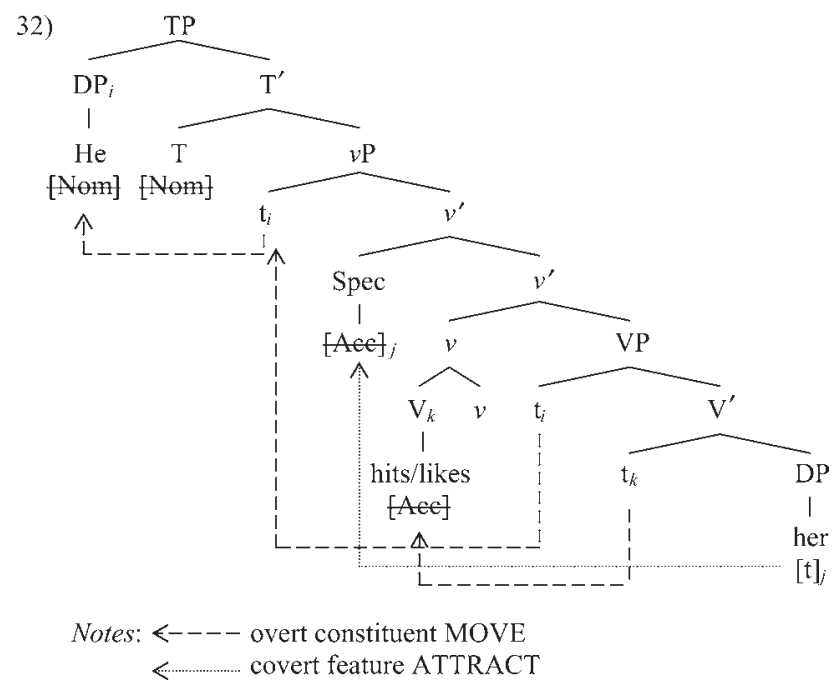

Since $\mathrm{T}$ in English requires overt movement of the subject, the subject He moves to the specifier position of $\mathrm{T}$, and the nominative Case is checked off by spec of T. The accusative Case of the object her raises to the specifier position of $v$, and it is eliminated by the accusative Case of $v$. Thus, it appears that these participants have acquired $\mathrm{V}, v$ and $\mathrm{T}$ in English and consequently accepted $\mathrm{Sub}(\mathrm{Nom}) / \mathrm{Obj}(\mathrm{Acc})$.

In addition to these analyses, we assume that the lexicon of substantive categories and that of functional categories are independent of one another and represented as distinct components (Tsimpli, 1992; 1995; Smith \& Tsimpli, 1995; Wakabayashi, 1997; 2002). This assumption is supported by our data. For instance, participants with Pattern 1 transferred $\mathrm{V}$ and its headedness, but not functional categories, and participants with Pattern 4 transferred a functional category $\mathrm{T}$, which allows two specifier positions. Hence, we conclude that all lexical items are not simultaneously transferred from Japanese, but each lexical item is transferred from Japanese independently. Without positing the involvement of lexical transfer in SLA in this way, it appears impossible to give a principled account for the behaviour of these participants. 


\section{Development of interlanguage grammar}

A summary of the JLEs' interlanguage grammars appears in (33).

33) a. Pattern 1: V was projected but the headedness was not fixed and the headedness of both languages was used.

b. Pattern 2: $\mathrm{V}$ was projected and headedness was acquired.

c. Pattern 3: Japanese lexical items such as $\mathrm{V}, v$ and $\mathrm{T}$ (and their features) were transferred.

d. Pattern 4: Japanese T (and its features) was transferred.

e. Pattern 5: English lexical items such as V, $v$ and $\mathrm{T}$ (and their features) were acquired.

Based on this analysis, we propose a developmental sequence in JLEs' interlanguage grammars illustrated in Figure 8. Participants in Group 1 exhibited Patterns 1,2 and 3. They were beginners and they had received the least exposure to English. In Group 1, two participants had transferred the headedness of VP from Japanese and two other participants had acquired it, but they were unable to take functional categories into the numeration (Pattern $1 \&$ Pattern 2). Four participants had transferred a full set of properties from Japanese and selected English choices following the Japanese case system (Pattern 3). These observations demonstrate that JLEs at a very early stage transfer the headedness and/or lexical items from Japanese.

Participants in Group 2 showed Patterns 2, 3, 4 and 5. They were also beginners, but they were different from the participants in Group 1 with respect to their more extensive exposure to English. According to our analysis, two participants had not acquired any functional categories and accepted Sub(Acc)/Obj(Acc) (Pattern 2); two other participants had transferred functional categories from Japanese and judged English

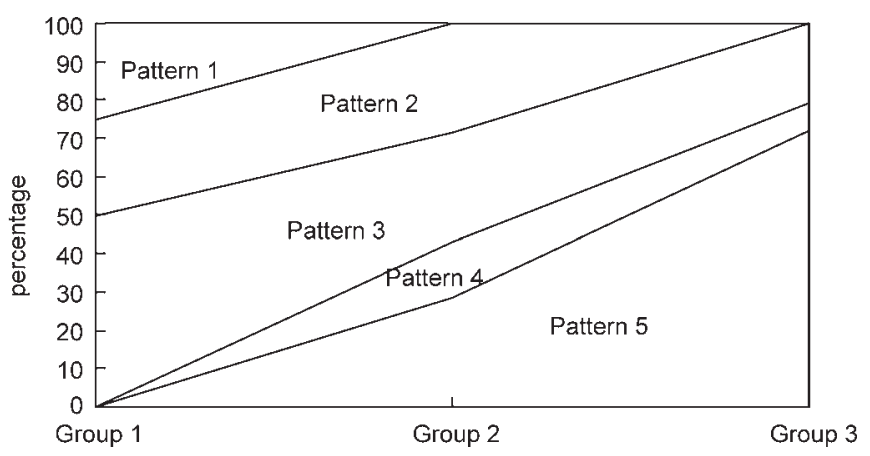

Figure 8 Developmental sequence in JLEs' interlanguage grammars 
choices in line with the Japanese case system (Pattern 3). One participant had transferred only a functional category $\mathrm{T}$, which allows multiple feature checking (Pattern 4), and two participants had acquired the lexical items of English and accepted the correct English choice (Pattern 5). This suggests that a full set of L1 lexical items is not transferred at the same time (contra the FT/FA).

Participants in Group 3 showed Patterns 3, 4 and 5. No participant showed Pattern 1 or 2, so all of them appear to have some functional category at this point, unlike participants in Groups 1 and 2. However, three participants still had transferred all lexical items (Pattern 3) and one participant had transferred a lexical item $\mathrm{T}$ from Japanese (Pattern 4). The remaining ten participants had acquired the lexical items in English and accepted the correct English choice (Pattern 5). Thus, we can see that transfer of lexical items took place in the early acquisition process and that this transfer persisted through at least 21 months of exposure to English. Drawing on our analysis of the data and our description of participants' interlanguage grammars, we consider the implications for SLA models in the next section.

\section{Examining the research assumptions}

a The Full Transfer/Full Access model: Under the FT/FA (Schwartz \& Sprouse, 1994; 1996; 2000; Schwartz, 1998), JLEs should accept $\mathrm{Sub}$ (Nom)/Obj(Acc), Sub(Nom)/Obj(Nom), Obj(Acc)/Sub(Nom) and $\mathrm{Obj}(\mathrm{Nom}) / \mathrm{Sub}(\mathrm{Nom})$ at early stages of acquisition since it is proposed that the L1 grammar fully transfers at the L2 initial state. In addition, as the FT/FA assumes that the L2 initial grammar will undergo restructuring under the constraints imposed by UG, JLEs should narrow their options to just $\mathrm{Sub}(\mathrm{Nom}) / \mathrm{Obj}(\mathrm{Acc})$ at some later stage. The FT/FA may be able to account for Pattern 3 (33c) and Pattern 5 (33e), and possibly Pattern 4 (33d). However, this model cannot explain the data exhibiting Pattern 1 (33a) and Pattern 2 (33b) because it does not propose that JLEs in early stages of development will behave in the same way as (child L1 learners and accept $\mathrm{Sub}(\mathrm{Acc}) / \mathrm{Obj}(\mathrm{Acc})$ and $\mathrm{Obj}(\mathrm{Acc}) / \mathrm{Sub}(\mathrm{Acc})$. In short, L1 transfer is not absolute, and the FT/FA is not supported by our data.)

$b$ The Minimal Trees model: If the MT hypothesis (Vainikka \& YoungScholten, 1994; 1996a; 1996b; 1998) were correct, JLEs would accept 
Obj(Acc)/Sub(Acc), Obj(Acc)/Sub(Nom), Sub(Nom)/Obj(Acc) and $\mathrm{Sub}(\mathrm{Acc}) / \mathrm{Obj}$ (Acc) at a very early stage since MT predicts that the headedness of VP is transferred at the initial stage of SLA. They would narrow their options to $\mathrm{Sub}(\mathrm{Nom}) / \mathrm{Obj}(\mathrm{Acc})$ at some later stage on the basis of functional properties triggered by English input. MT can account for the data exhibiting Pattern 1 (33a) and Pattern 5 (33e). It can also explain Pattern 2 (33b) if we assume that JLEs acquired the target value for the headedness of VP at this stage. However, this model cannot account for Patterns 3 (33c) or 4 (33d), where the transfer of Japanese lexical items (and their features) took place. Because the transfer of the features of a functional category is shown in our data, MT is not supported.

c The Lexical Learning/Lexical Transfer model: If the LL/LT (Wakabayashi, 1997; 2002) was correct, JLEs would accept $\mathrm{Sub}(\mathrm{Acc}) / \mathrm{Obj}$ (Acc) and $\mathrm{Sub}(\mathrm{Nom}) / \mathrm{Obj}$ (Acc) by lexical learning and $\mathrm{Sub}(\mathrm{Nom}) / \mathrm{Obj}$ (Acc) and $\mathrm{Sub}(\mathrm{Nom}) / \mathrm{Obj}(\mathrm{Nom})$ by L1 transfer in early stages, and then $\mathrm{Sub}(\mathrm{Nom}) / \mathrm{Obj}(\mathrm{Acc})$ at some later stage. As seen in the previous subsection, this pattern emerged in our data. ${ }^{19}$ The participants whose responses exhibited Patterns 1 (33a) and 2 (33b) accepted $\mathrm{Sub}(\mathrm{Acc}) / \mathrm{Obj}(\mathrm{Acc})$ in the same way that child L1 learners do; those with Patterns 3 (33c) and 4 (33d) accepted Sub(Nom)/Obj(Acc) and $\mathrm{Sub}(\mathrm{Nom}) / \mathrm{Obj}$ (Nom) because they had transferred lexical items and their features from Japanese; and those with Pattern 5 (33e) accepted $\mathrm{Sub}(\mathrm{Nom}) / \mathrm{Obj}$ (Acc) because they had acquired the functional categories $v$ and $\mathrm{T}$ as well as $\mathrm{V}$ in English. What needs to be emphasized here is that JLEs gradually acquire the functional categories and features of the target grammar and that L1 transfer of lexical items takes place in the course of development of an L2 grammar. Hence, if our discussion is on the right track, it is reasonable to propose that neither FT/FA nor MT can fully explain our JLEs' data, while LL/LT can.

\section{Other issues}

So far our discussion has been based on the assumption that morphological evidence can be used to discuss learners' syntactic knowledge.

${ }^{19} \mathrm{The}$ LL/LT says nothing about the transfer of headedness, but it can be assumed that a lexical item $\mathrm{V}$ with its headedness is transferred if lexical transfer takes place in SLA as the LL/LT predicts. 
Accusative case-marking is considered to reflect a feature [ACC] or [default] of an NP, while nominative case-marking is considered to reflect a feature [NOM]. However, if we assume that morphological data do not reflect learners' syntactic knowledge, as assumed by the Missing Surface Inflection hypothesis (Haznedar \& Schwartz, 1997; Prévost \& White, 2000; see also Lardiere, 1998a; 1998b; 2000), our discussion may be irrelevant.

If we assume that a default form is available for L2 learners and morphology is dissociated from syntax, our data may be consistent with the FT/FA. In the first stage, the default form is used despite complete transfer of the L1 syntax; in a later stage, L2 learners associate some forms with some features but L1 transfer still persists; in a final stage, they acquire target-like syntactic knowledge and this knowledge is reflected in the relevant morphemes. However, there are two problems with this line of reasoning.

One is theoretical. According to this reasoning, because morphological evidence may not be relied upon to discuss syntactic knowledge, we cannot be sure whether L2 learners have acquired relevant features even when they consistently use the target form. In fact, no morphological evidence can be used to discuss syntactic knowledge, including formal features, because we assume dissociation between syntax and morphology in the first place. We need a model to discuss morphological development which must be independent of syntactic theory. However, no such model, which might explain our data, has been offered in SLA research as far as we are aware.

The other problem is empirical. If L1 transfer takes place at the beginning of SLA, L2 learners are not expected to use accusative forms as defaults. It is widely reported that children use nominative casemarking as a default in the acquisition of Japanese as an L1 (e.g., Suzuki, 1999). Hence, if SLA starts from the L1 grammar, L2 learners should use either the form equivalent in their L1 or the default form available in their L1. ${ }^{20}$ The use of the accusative form as default at an early stage is not expected.

\footnotetext{
${ }^{20}$ Kuroda (1978) suggests that the nominative case marker - ga is the default form even in the adult grammar of Japanese.
} 


\section{Conclusions}

In this study we investigated the acquisition of pronominal casemarking by JLEs. Data were collected from three experimental groups. Examination of those data suggested that:

34) a. Each lexical item is transferred from the L1 in SLA at a given point of development.

b. Lexical items are acquired in SLA.

We maintain that an SLA account must explain the phenomena of lexical learning as in L1 acquisition and lexical transfer from the L1 lexicon in SLA. We conclude that neither FT/FA nor MT can fully capture our data, while LL/LT does.

This study shows that lexical learning and lexical transfer take place in SLA. However, several unresolved questions remain. For instance, there appear to exist individual differences concerning the course and rate of L2 grammatical development, but such differences were not examined in detail. Furthermore, the study dealt with cross-sectional data, and hence developmental data from individual participants are required for further study. In addition, we collected data using a translation matching task under restricted conditions. To examine mechanisms of SLA further, other types of data may be helpful. Furthermore, the LL/LT model may suffer from the ability to explain any kind of patterns observed in interlanguage grammars. However, there may be some (or many) properties that will not be acquired or will be difficult to acquire even after long periods of exposure to the target language. These are issues to address in future research.

\section{Acknowledgements}

This article is a modified version of Suda (2000), and some parts of the results of the experiment were reported in Suda and Wakabayashi (2002; 2003). Early versions were presented at the 17 th annual meeting of the Japanese Cognitive Science Society, Shizuoka University of Arts and Culture, July 2000; the 10th annual conference of EUROSLA, the Instytut Polonijny i Hotel, Poland, September 2000; and PacSLRF, University of Hawai'i at Manoa, October 2001. This study was partly supported by Grants-in-Aid for Scientific Research (c) (2) No. 15520364 from the Japan Society for the Promotion of Science to Shigenori 
Wakabayashi. We would like to thank the participants at our talks for helpful comments. All the remaining shortcomings are of course ours.

\section{References}

Aldridge, M. 1989: The acquisition of INFL. Bloomington, IN: Indiana University Linguistic Club.

Chomsky, N. 1995: The minimalist program. Cambridge, MA: MIT Press.

- 2000: Minimalist inquiries: the framework. In Martin, R., Michaels, D. and Uriagereka, J., editors, Step by step: essays on minimalist syntax in honor of Howard Lasnik. Cambridge, MA: MIT Press, 89-155.

Clahsen, H., Eisenbeiss, S. and Penke, M. 1996: Lexical learning in early syntactic development. In Clahsen, H., editor, Generative perspectives on language acquisition. Amsterdam: John Benjamins, 129-59.

Clahsen, H., Eisenbeiss, S. and Vainikka, A. 1994: The seeds of structure: a syntactic analysis of the acquisition of case-marking. In Hoekstra, T. and Schwartz, B., editors, Language acquisition studies in generative grammary. Amsterdam: John Benjamins, 85-118.

Culicover, P. 1997: Principles and parameters: an introduction to syntactic theory. Oxford: Oxford University Press.

Dube, B. 2000: Where are the minimal trees? Evidence from early Zulu L2 subordination. Second Language Research 16, 233-65.

Harada, S. 1976: Honorifics. In Shibatani, M., editor, Syntax and Semantics, volume 5: Japanese Generative Grammar. New York: Academic Press, 499-561.

Haznedar, B. and Schwartz B.D. 1997: Are there optional infinitives in child second language acquisition? In Hughes, E., Hughes, M. and Greenhill, A., editors, Proceedings of the 21st annual Boston University conference on language development. Somerville, MA: Cascadilla Press.

Ito, M. 2001: Case marking and verb morphology in early syntactic development. Fukuoka: Kyushu University Press.

Kitagawa, Y. 1986: Subjects in Japanese and English. Unpublished PhD dissertation, University of Massachusetts, Amherst, MA.

Koizumi, M. 1995: Phrase structure in minimalist syntax. Unpublished $\mathrm{PhD}$ dissertation, MIT, Cambridge, MA.

Kuno, S. 1973: The structure of the Japanese language. Cambridge, MA: MIT Press.

Kuroda, S.-Y. 1978: Case marking, canonical sentence patterns, and counter equi in Japanese (a preliminary survey). In Hinds, J. and Howard, I., editors, Problems in Japanese syntax and semantics. Tokyo: Kaitakusya, 30-51. 1988: Whether we agree or not: a comparative syntax of English and Japanese. Linguisticae Investigationes 12, 1-47.

Lardiere, D. 1998a: Case and tense in the 'fossilized' steady state. Second language research $14,1-26$. 
— 1998b: Dissociating syntax from morphology in a divergent end-state grammar. Second language research 14, 359-75.

- 2000: Mapping features to forms in second language acquisition. In Archibald, J., editor, Second language acquisition and linguistic theory. Oxford: Blackwell, 102-29.

Mihara, K. 1994: Nihongo-no toogokouzou [Japanese syntactic structure]. Tokyo: Shouhakusha.

O'Grady, W. 1997: Syntactic development. Chicago, IL: University of Chicago.

Prévost, P. and White, L. 2000: Missing surface inflection or impairment in second language acquisition? Evidence from tense and agreement. Second Language Research 16, 103-33.

Radford, A. 1990: Syntactic theory and the acquisition of English syntax. Oxford: Blackwell.

1996: Toward a structure-building model of acquisition. In Clahsen, H., editor, Generative perspectives on language acquisition. Amsterdam: John Benjamins, 43-89.

- 1997: Syntactic theory and the structure of English. Cambridge: Cambridge University Press.

Saito, M. 1982: Case-marking in Japanese: a preliminary study. Unpublished paper, MIT, Cambridge, MA.

— 1985: Some asymmetries in Japanese and their theoretical implications. Unpublished PhD dissertation, MIT, Cambridge, MA.

Schütze, C. and Wexler, K. 1996: Subject case licensing and English root infinitives. In Stringfellow, A., Cahan-Amitay, D., Hughes, E. and Zukowski, A., editors, Proceedings of the 20th Boston University Conference on Language Development. Cambridge, MA: MIT Press, 670-81.

Schwartz, B.D. 1998: The second language instinct. Lingua 106, 133-60.

Schwartz, B.D. and Sprouse, R.A. 1994: Word order and nominative case in nonnative language acquisition: a longitudinal study of (L1 Turkish) German interlanguage. In Hoekstra, T. and Schwartz, B., editors, Language acquisition studies in generative grammar. Amsterdam: John Benjamins, 317-68.

— 1996: L2 cognitive states and the full transfer/full access model. Second Language Research 12, 40-72.

2000: When syntactic theories evolve: consequences for second language acquisition research. In Archibald, J., editor, Second language acquisition and linguistic theory. Oxford: Blackwell, 156-86.

Shibatani, M. 1990: The languages of Japan. Cambridge: Cambridge University Press.

Smith, N. and Tsimpli, I.-M. 1995: The mind of a savant. Oxford: Blackwell.

Suda, K. 2000: The acquisition of case by Japanese learners of English. Unpublished MA thesis, Gunma Prefectural Women's University, Tamamura, Japan. 


\section{The acquisition of pronominal case-marking}

Suda, K. and Wakabayashi, S. 2002: Pronominal case-marking by Japanese learners of English. In Shirai, Y., Kobayashi, H., Miyata, S., Nakamura, K., Ogura, T. and Sirai, H., editors, Studies in language sciences 2. Tokyo: Kurosio, 227-42.

- 2003: The acquisition of the nominative and accusative cases in English by Japanese learners at an early stage. In Wakabayashi, S., editor, Generative approaches to the acquisition of English by native speakers of Japanese. Berlin: Mouton de Gruyter, 81-107.

Suzuki, T. 1999: Two aspects of Japanese case in acquisition. Unpublished $\mathrm{PhD}$ dissertation, University of Hawai'i, Honolulu, HI.

Takezawa, K. and Whitman, J. 1998: Kaku-to gozyun-to toogokouzou [Case, word order and syntactic structure]. Tokyo: Kenkyuusya.

Tateishi, K. 1991: The syntax of 'subjects'. Unpublished PhD dissertation, University of Massachusetts, Amherst, MA.

Thomas, M. 1991: Universal grammar and the interpretation of reflexives in a second language. Language 67, 211-41.

Tsimpli, I.-M. 1992: Functional categories and maturation: the prefunctional stage of language acquisition. Unpublished $\mathrm{PhD}$ dissertation, University College London.

— 1995: The prefunctional stage of first language acquisition: a crosslinguistic study. New York: Garland.

Ura, H. 1996: Multiple feature-checking: a theory of grammatical function splitting. Unpublished PhD dissertation, MIT, Cambridge, MA.

Vainikka, A. 1993/94: Case in the development of English syntax. Language Acquisition 3, 257-25.

Vainikka, A. and Young-Scholten, M. 1994: Direct access to X'-theory: evidence from Korean and Turkish adults learning German. In Hoekstra, T. and Schwartz, B., editors, Language acquisition studies in generative grammar. Amsterdam: John Benjamins, 265-316.

— 1996a: Gradual development of L2 phrase structure. Second Language Research 12, 7-39.

— 1996b: The early stages of adult L2 syntax: additional evidence from Romance speakers. Second Language Research 12, 140-76.

_ 1998: The initial state in the second language acquisition of phrase structure. In Flynn, S., Martohardjono, G. and O'Neil, W., editors, The generative study of second language acquisition. Mahwah, NJ: Lawrence Erlbaum, 17-34.

Wakabayashi, S. 1997: The acquisition of functional categories by learners of English. Unpublished $\mathrm{PhD}$ dissertation, University of Cambridge.

— 2002: The acquisition of non-null subjects in English: a minimalist account. Second Language Research 18, 28-71.

Wexler, K. 1998: Very early parameter setting and the unique checking constraint: a new explanation of the optional infinitive stage. Lingua 106, 23-79. 